Pesq. Vet. Bras. 38(5):811-816, maio 2018

\title{
Fotossensibilização primária em bovinos leiteiros causada por Froelichia humboldtiana ${ }^{1}$
}

\author{
Sheila N.R. Knupp ${ }^{2 *}$, Caio Cesar Borburema ${ }^{3}$, Valber O. Araújo ${ }^{3}$, Thatyana K.F. Silva ${ }^{3}$, \\ Franklin Riet-Correa ${ }^{4}$, Leonardo S. Knupp ${ }^{5}$ e Ricardo B. Lucena ${ }^{3}$
}

ABSTRACT.- Knupp S.N.R., Borburema C.C., Araújo V.O., Silva T.K.F., Riet-Correa F., Knupp L.S. \& Lucena R.B. 2018. [Primary photosensitization in dairy cattle caused by Froelichia humboldtiana.] Fotossensibilização primária em bovinos leiteiros causada por Froelichia humboldtiana. Pesquisa Veterinária Brasileira 38(5):811-816. Departamento de Medicina Veterinária, Centro de Saúde e Tecnologia Rural, Universidade Federal de Campina Grande, Campus de Patos, Avenida Universitária s/n, Bairro Santa Cecília, Cx. Postal 61, Patos, PB 58708-110, Brazil. E-mail: sheilanribeiro@hotmail.com

The present study was conducted with the objective to report an outbreak of photosensitization caused by Froelichia humboldtiana in dairy cattle in the State of Rio Grande do Norte, Brazil. Animals from a rural property with symptoms compatible with photodermatitis were examined. Peripheral blood samples from five cattle were collected for the analysis of the activities of hepatic enzymes gammaglutamyltransferase and aspartate aminotransferase, in addition were also analysed the concentration of total, direct and indirect bilirubin. From the areas of skin with lesions of two animals, biopsies were performed. It was verified that 15 animals from a herd composed by 40 animals presented photosensitization. The animals had a history of photodermatitis lesions approximately 10 days after grazing in areas invaded by F. humboldtiana. Clinical examination of dairy cattle showed that they initially had pruritus and hyperemia in the depigmented areas of the dorsum and udder, and there were also behavioral changes. Subsequently, the hyperemic areas presented edema that evolved to ulcerative, necrotizing and exudative dermatitis, with loss of extensive areas of the epidermis. The ulcers were more severe in four bovines that had self-mutilation by licking. These four animals were removed from the pasture and sheltered in a shady location. A week later, the pruritus regressed and the fissures of the skin began to heal. However, the lesions reappeared after the cattle were reintroduced in the grass infested by $F$. humbolditiana. There was also a decrease in milk production (reduction of 50-60\%) of cows after the installation of photodermatitis. However, calves that were still lactating and ingested the milk in photosensitized cows, showed no signs of photodermatitis. Histopathology of skin biopsies revealed inflammation in the superficial dermis consisting of mast cells, lymphocytes, and some plasma cells. In the epidermis there were extensive ulcers, covered by crusts, associated with neutrophilic infiltrate. Serum activities of AST, GGT and bilirubin concentrations were within normal reference values for the bovine species. The diagnosis of primary photosensitization associated with $F$. humboldtiana ingestion was based on epidemiology, clinical signs, serum biochemistry, skin biopsy and lesion reoccurrence after the animals were reintroduced in the pasture invaded by the plant.

\footnotetext{
${ }^{1}$ Recebido em 24 de janeiro de 2017.

Aceito para publicação em 26 de abril de 2017.

${ }^{2}$ Programa de Pós-graduação em Medicina Veterinária, Centro de Saúde e Tecnologia Rural (CSTR), Universidade Federal de Campina Grande (UFCG), Avenida Universitária s/n, Bairro Santa Cecília, Patos, PB 58708-110, Brasil. *Autor para correspondência: sheilanribeiro@hotmail.com

${ }^{3}$ Laboratório de Patologia Veterinária, Departamento de Ciências Veterinárias, Centro de Ciências Agrárias, Universidade Federal da Paraíba (UFPB), Campus II, Cidade Universitária, Areia, PB 58397-000, Brasil.
}

\footnotetext{
E-mails: caioborburema@hotmail.com, valber.onofre@hotmail.com, ta_tykelly@hotmail.com, lucena.rb@gmail.com

${ }^{4}$ Unidade Acadêmica de Medicina Veterinária, Centro de Saúde e Tecnologia Rural (CSTR), Universidade Federal de Campina Grande (UFCG), Avenida Universitária s/n, Bairro Santa Cecília, Patos, PB 58708-110. E-mail: franklin. riet@pq.cnpq.br

${ }^{5}$ Programa de Pós-Graduação Integrado em Zootecnia, Centro de Ciências Agrárias, Universidade Federal da Paraíba (UFPB), Campus II, Cidade Universitária, Areia, PB 58397-000. E-mail: leonardoknupp@hotmail.com
} 
It is concluded that $F$. humboldtiana is an important cause of primary photosensitization in dairy cattle in the Brazilian semi-arid region and that its toxin is probably not excreted by bovine milk.

INDEX TERMS: Poisonous plants, photosensitization, cattle, ervanço, Froelichia humboldtiana, Amaranthaceae, plant poisoning, ruminants, photodermatitis, toxicoses.

RESUMO.- 0 presente trabalho foi conduzido com o objetivo de relatar um surto de fotossensibilização causado por Froelichia humboldtiana em bovinos leiteiros no Estado do Rio Grande do Norte, Brasil. Foram examinados animais de uma propriedade rural que apresentavam sintomatologia compatível com fotodermatite. Procedeu-se a coleta de amostras de sangue periférico de cinco bovinos para análise das atividades das enzimas hepáticas gamaglutamiltransferase e aspartatoaminotransferase, além da concentração de bilirrubina total, direta e indireta. Das áreas de pele com lesões de dois animais foram realizadas biópsias. Constatou-se que 15 animais de um rebanho composto por 40 animais apresentaram fotossemsibilização. Os animais tinham histórico de apresentar lesões de fotodermatite aproximadamente 10 dias após pastarem em áreas invadidas por F. humboldtiana. Ao exame clínico dos bovinos leiteiros notou-se que inicialmente apresentavam prurido e hiperemia nas áreas de pele despigmentadas do dorso e úbere, também havia alterações do comportamento. Posteriormente, as áreas hiperêmicas se apresentavam com edema que evoluíam para dermatite ulcerativa, necrotizante e exudativa, com perda de extensas áreas da epiderme. As úlceras eram mais graves nos quatro bovinos que apresentavam automutilação por lambedura. Esses quatro animais foram retirados do pasto e abrigados em local sombreado. Uma semana após, o prurido regrediu e as fissuras da pele passaram a cicatrizar. Porém, as lesões reapareceram logo após os bovinos serem reintroduzidas no pasto infestado por $F$. humbolditiana. Percebeu-se ainda queda na produção leiteira (redução de 50-60\%) das vacas após a instalação de fotodermatite. Porém, os bezerros que ainda eram lactantes e ingeriam o leite nas vacas acometidas por fotossensibilização, não apresentaram sinais de fotodermatite. A histopatologia de biópsias de pele revelou inflamação na derme superficial constituída por mastócitos, linfócitos, e alguns plasmócitos. Na epiderme haviam extensas úlceras, recobertas por crostas, associada a infiltrado neutrofílico. As atividades séricas de AST, GGT e as concentrações de bilirrubina estavam dentro dos valores de referência normais para a espécie bovina. 0 diagnóstico de fotossensibilização primária associada à ingestão de F. humboldtiana foi baseado na epidemiologia, sinais clínicos, bioquímica sérica, biópsia de pele e reocorrência das lesões após os animais serem reintroduzidos no pasto invadido pela planta. Conclui-se que a F. humboldtiana é uma importante causa de fotossensibilização primária em bovinos leiteiros no semiárido brasileiro e que sua toxina provavelmente não é excretada pelo leite bovino.

TERMOS DE INDEXAÇÃO: Plantas tóxicas, ervanço, Froelichia humboldtiana, Amaranthaceae, fotossensibilização primária, intoxicação por plantas, bovinos, ruminantes, fotodermatite, toxicoses.

\section{INTRODUÇÃO}

Froelichia humboldtiana (Amaranthaceae) é uma planta amplamente distribuída na região Nordeste brasileira e também encontrada em algumas áreas do Centro-Oeste do Brasil (Marchioretto et al. 2002).

A fotossensibilização ocasionada por $F$. humboldtiana é bem conhecida na região semiárida do Nordeste do Brasil, afetando principalmente equídeos (Pimentel et al. 2007, Knupp et al. 2014, Medeiros et al. 2014). Porém os criadores alegam que a doença ocasionada pela planta, popularmente conhecida como ervanço, também afeta ovelhas e bovinos (Macedo et al. 2006), além de caprinos (Santos et al. 2016). Fato este comprovado em surtos de fotossensibilização primária causados por $F$. humboldtiana afetando bovinos de corte (Souza et al. 2012), ovinos (Pimentel et al. 2007), e caprinos (Souza et al. 2012, Santos et al. 2016) seguidos de experimentação científica. Todavia, não existem relatos de surtos naturais de fotossensibilização em bovinos leiteiros causados pela ingestão do ervanço. Neste estudo descrevem-se casos naturais de fotossensibilização primária associada à ingestão de F. humboldtiana em bovinos leiteiros no Nordeste do Brasil.

\section{MATERIAL E MÉTODOS}

Os dados epidemiológicos e as avaliações clínicas foram obtidos a partir de visitas a uma fazenda de bovinos leiteiros mestiços de Gir, Girolando, Holandês e Jersey acometidos por doença cutânea no município de Assú, estado do Rio Grande Norte, Brasil. 0 município de Assú $\left(05^{\circ} 34^{\prime} 37,2^{\prime \prime}\right.$ de latitude sul e 3654'32,4" de longitude oeste) está localizado em região semi-árida do nordeste brasileiro de clima seco e muito quente, com apenas duas estações bem definidas, estação chuvosa de março a abril, e seca no restante do ano, com média pluviométrica de 750,8mm (IDEMA 2008).

0 histórico clínico foi obtido em entrevistas com os proprietários e médicos veterinários que atenderam os bovinos anteriormente. Foram feitas ainda duas visitas à fazenda no final dos meses de março e maio do ano de 2016 para avaliação clínica dos bovinos. Das áreas de pele de dois bovinos com dermatite foram realizadas biópsias. As amostras colhidas foram fixadas em formol tamponado $10 \%$ e posteriormente processadas rotineiramente e coradas com hematoxilina e eosina (HE), ácido periódico de Schiff (PAS) e prata metenamina de Grocott (GMS).

No soro de cinco bovinos foram determinadas as atividades das enzimas aspartato-aminotransferase (AST) e gama-glutamiltransferase (GGT), além da dosagem de bilirrubina total, direta e indireta.

\section{RESULTADOS}

O surto de fotodermatite acometeu um rebanho constituído por 40 bovinos mestiços de Girolando, Gir, Holandês e Jersey. Desses, 12 eram vacas em fase de lactação, com 12 bezerros ao pé; 10 eram bovinos jovens com idade entre um e dois anos; quatro vacas prenhas; um touro adulto; e um touro jovem com 
aproximadamente três anos de idade. Os bovinos pastavam em área de pasto nativo. Durante o final da tarde, as vacas em lactação eram removidas para o curral e suplementadas com ração concentrada e balanceada, além de capim elefante (Pennisetum purpureum) triturado. Sal mineral, fórmula comercializada para bovinos, e água eram fornecidos à vontade.

Os casos de fotodermatite ocorreram entre os meses de março a maio, época do período de chuvas no município de Assú, no ano de 2016. A pastagem onde os bovinos estavam apresentava predominantemente Froelichia humboldtiana em avançada floração e desenvolvimento de pendão (Fig.1). De acordo com informações dos criadores e observações durante as visitas, constatou-se que F. humboldtiana é palatável para bovinos.

0 quadro de fotossensibilização variou de leve a acentuado e acometeu 15 animais (37\%). Sendo afetadas oito vacas em lactação, seis bovinos jovens e um touro. Segundo informações do proprietário, os sinais evidentes de fotodermatite iniciaram aproximadamente 10 dias após os bovinos serem colocados no pasto infestado por $F$. humbolditiana. 0 quadro foi mais grave nos bovinos mestiços de Holandês com áreas de pele despigmentada, mas também acometeu bovinos pigmentados. Inicialmente os bovinos apresentavam prurido e hiperemia nas áreas de pele despigmentadas do dorso e úbere (Fig.2). Notavam-se alterações do comportamento, caracterizadas por inquietação /estresse, com o balançar incessante da cauda e lambedura compulsiva da pele. Posteriormente, as áreas hiperêmicas se apresentavam com edema que evoluía para dermatite ulcerativa, necrotizante e exudativa, com perda de extensas áreas da epiderme (Fig.3A). As úlceras eram mais graves em quatro bovinos que apresentavam automutilação por lambedura (Fig.3B-D).

A avaliação da produção de leite, realizada na ordenha pela manhã, revelou que após a instalação de fotodermatite, as vacas acometidas tiveram uma queda na produção de quatro a seis litros (50-60\%), além de emagrecimento. Porém, os bezerros que ainda eram lactantes e ingeriam o leite nas

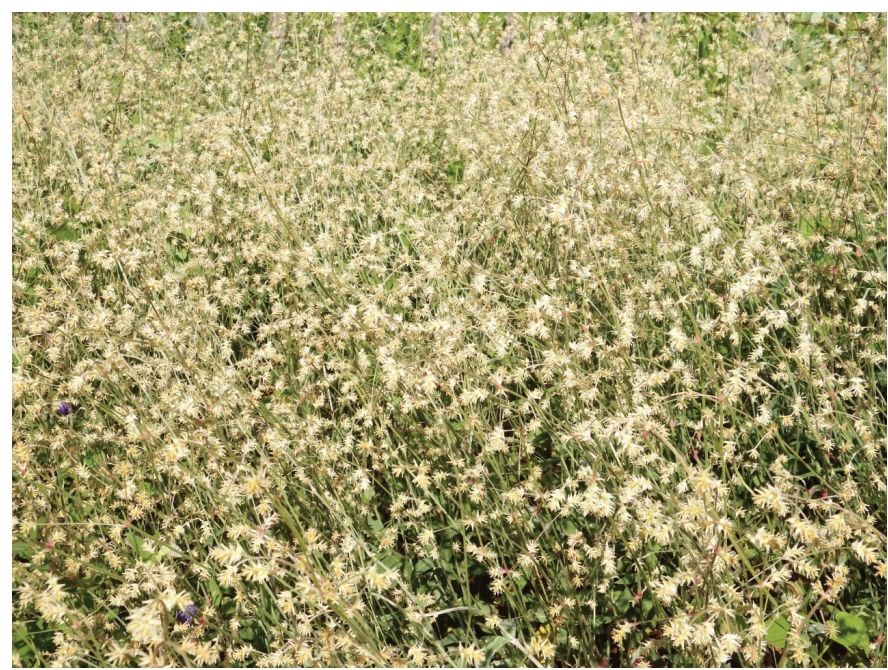

Fig.1. Pastagem intesamente invadida por ervanço (Froelichia humboldtiana) em fase de floração.
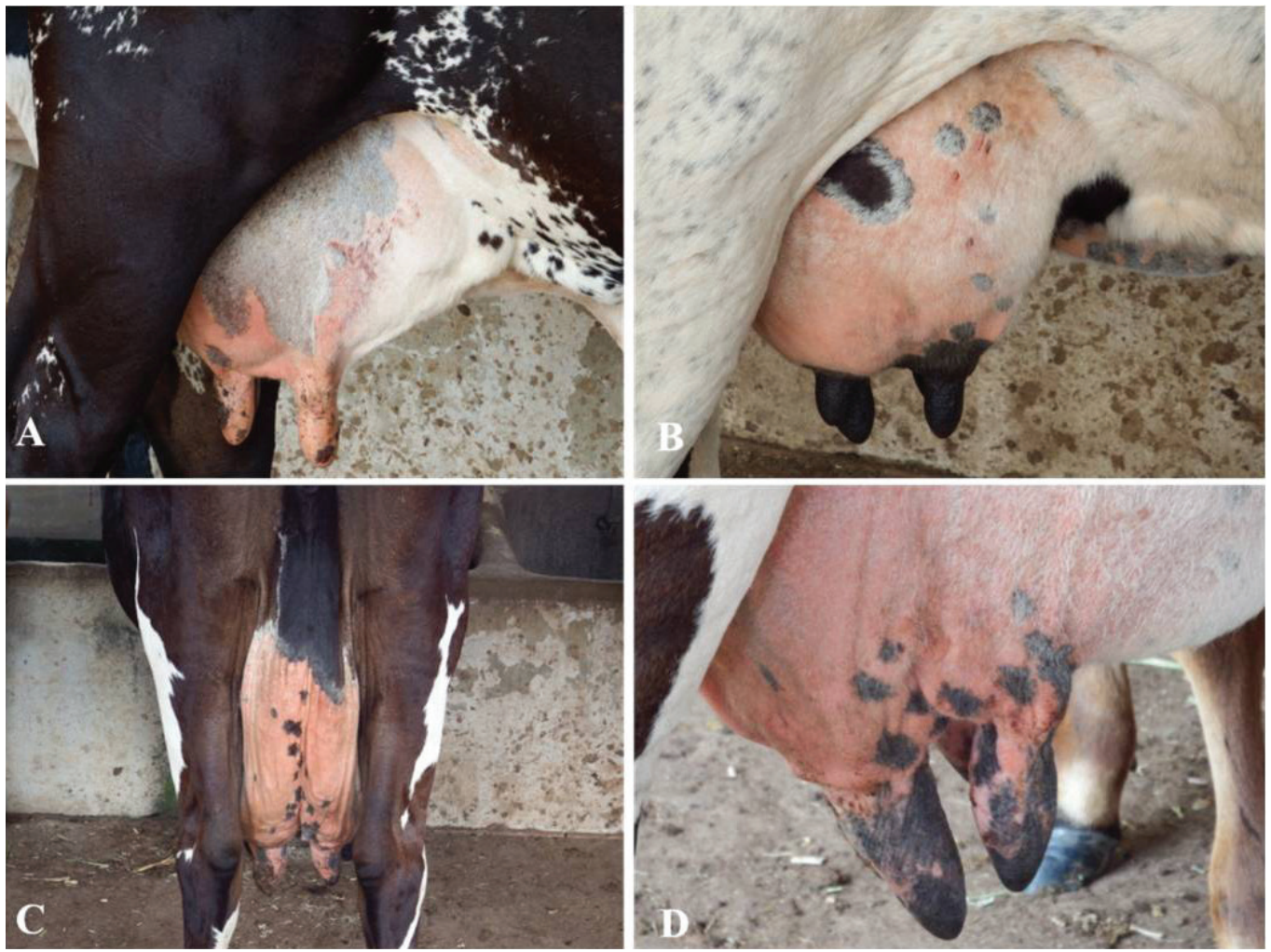

Fig.2. (A-D) Fotodermatite causada por ingestão de Froelichia humboldtiana em bovinos. Vacas com pele do úbere marcadamente hiperêmica. Nota-se que as úlceras desenvolveram-se basicamente nas áreas não pigmentadas. 

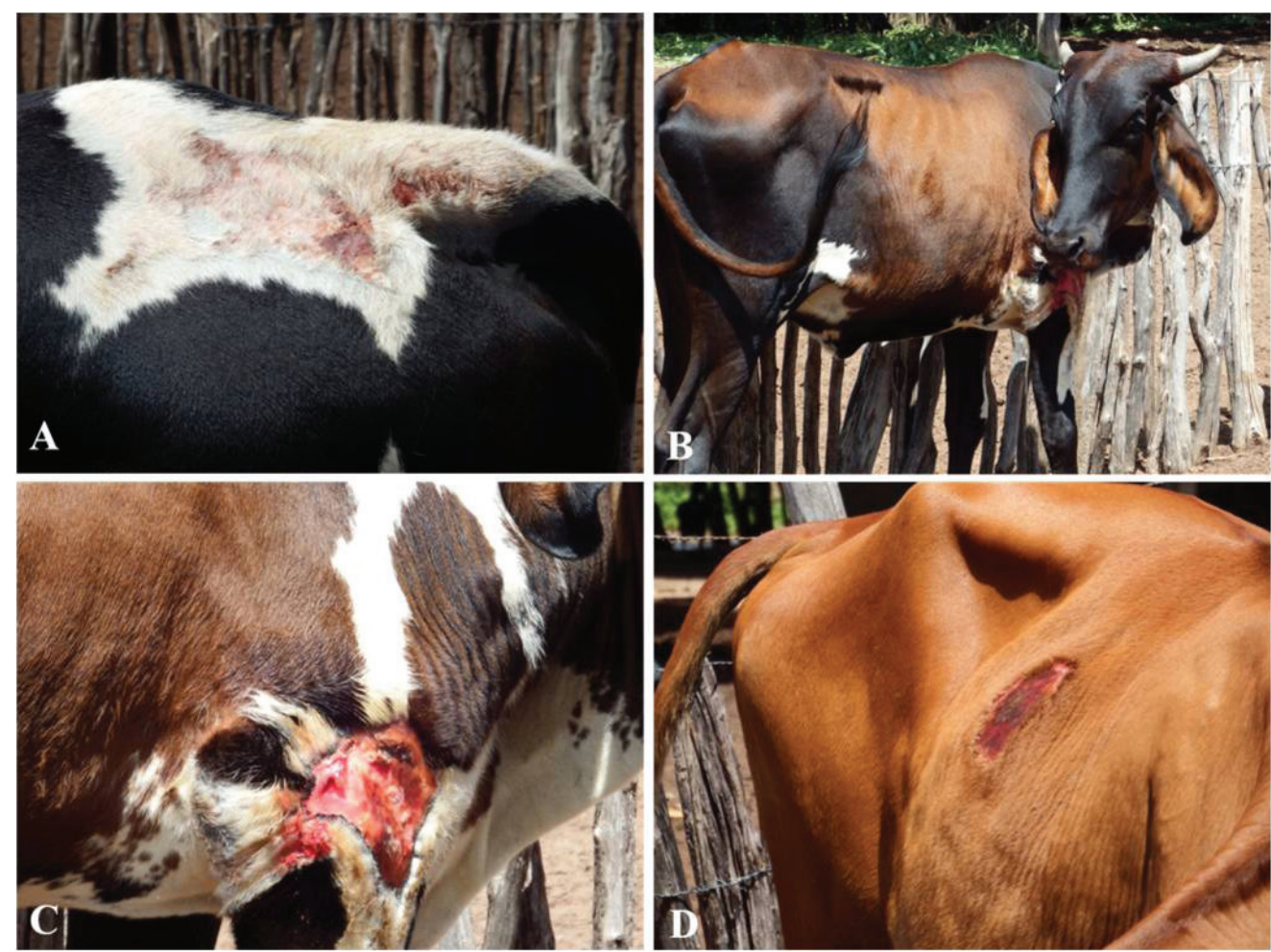

Fig.3. (A) Fotodermatite causada por ingestão de Froelichia humboldtiana em bovinos. Extensas áreas ulceradas na pele não pigmentada de um bovino Holandês. (B) Novilha mestiça apresentando lambedura na região escapulo-umeral, devido ao intenso prurido causado pela fotossensibilização primária. (C) Extensa ferida cutânea resultante da automutilação. (D) Área alopécica e ulcerada no tórax lateral causada por lambedura em uma novilha mestiça acometida por fotossensibilização primária.

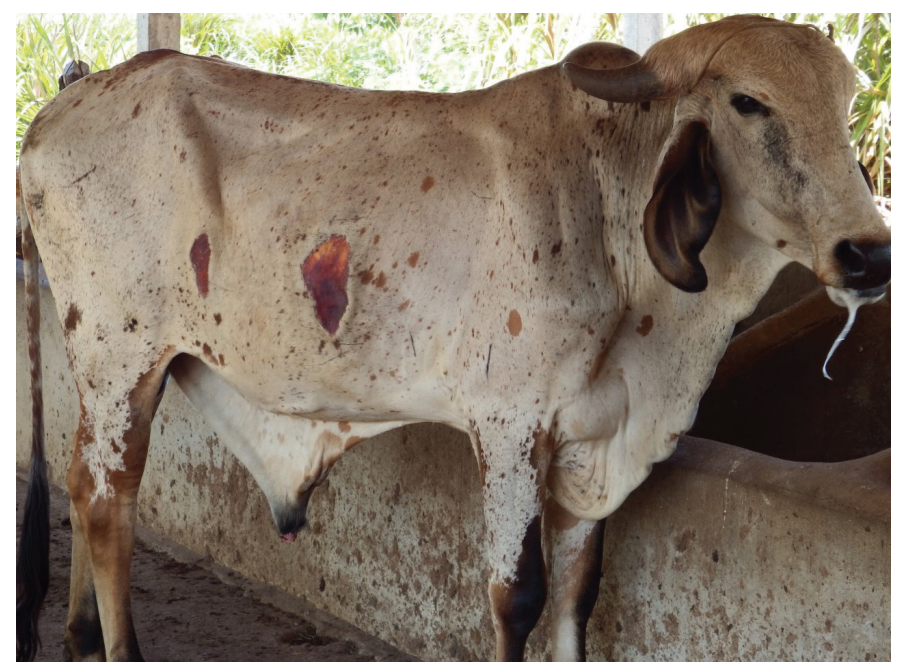

Fig.4. Fotodermatite causada por ingestão de Froelichia humboldtiana em bovino. Novilho Gir mantido em local sombreado durante seis dias, em fase de recuperação. Nesta fase não há mais prurido e as feridas causadas por lambedura estão em início de cicatrização.

vacas acometidas por fotossensibilização, não apresentaram sinais de fotodermatite.

Os bovinos com lesão de automutilação foram retirados do pasto e abrigados em local sombreado. Uma semana após, o prurido regrediu e as fissuras da pele passaram a cicatrizar (Fig.4). Porém, as lesões reapareceram logo após os bovinos serem reintroduzidas no pasto infestado por $F$. humbolditiana. 0 fazendeiro optou por não retirar do pasto os bovinos que não apresentavam sinais de automutilação. 0 prurido e as lesões de pele destes cessaram no final do mês de maio, quando a planta sementou e amadureceu.

A histopatologia de biópsias de pele revelou inflamação na derme superficial, circundando vasos sanguíneos, constituída por mastócitos, linfócitos, e alguns plasmócitos. Na epiderme haviam extensas úlceras, recobertas por crostas, associada a infiltrado neutrofílico e por vezes numerosos agregados bacterianos basofílicos superficiais. Na avaliação com PAS e GMS, não foram observadas hifas fúngicas. As atividades séricas de AST, GGT e as concentrações de bilirrubina estavam dentro dos valores de referência normais para a espécie bovina.

\section{DISCUSSÃO}

O ervanço é uma planta altamente palatável para diversas espécies animais, como ovinos, equídeos e bovinos e, mesmo quando em menor quantidade, os animais tendem a selecioná-lo em sua alimentação (Macedo et al. 2006, Pimentel et al. 2007, Knupp et al. 2014). Em decorrência de sua grande disponibilidade, considerando-se a ocorrência do surto durante os meses chuvosos da região, associada à alta palatabilidade, e ao estágio de floração da planta, resultou-se no surto de fotossensibilização em bovinos leiteiros.

Segundo Knight \& Walter (2001), os pigmentos polifenólicos presentes em algumas plantas causam fotossensibilização primária em animais com pele não pigmentada, como foi observado nos bovinos do presente estudo, no entanto, alguns 
bovinos também desenvolveram sinais de prurido intenso em áreas pigmentadas e manifestação de automutilação por lambedura. Lesões semelhantes foram vistas em bovinos de corte (Souza et al. 2012). Automutilação associada ao prurido ocasionado pela fotossensibilização também foi descrita em cabra de pele pigmentada que pastava em área infestada por ervanço (Santos et al. 2016) e em asininos (Knupp et al. 2014).

O diagnóstico de intoxicação e fotossensibilização primária por Froelichia humboldtiana deste surto baseou-se na epidemiologia, nos sinais clínicos, na bioquímica sérica e na avaliação histológica das feridas de alguns animais. As atividades séricas da AST, GGT e as concentrações séricas de bilirrubina permaneceram dentro dos limites normais, demonstrando que a fotossensibilização foi primária e não secundária à doença hepática.

Outras doenças podem ocasionar sintomatologia semelhante à fotossensibilização primária em bovinos, como a dermatite por picada de insetos, a estefanofilariose, a pitiose e a fotossensibilização secundária. No caso da dermatite por picada de insetos, a presença de eosinófilos nos achados histopatológicos é compatível com um processo alérgico (Barbosa et al. 2011). Quanto à estefanofilariose, é uma enfermidade causada por um nematódeo do gênero Stephanofilaria (Johnson et al. 1981), o qual não foi observado no exame histopatológico da ferida. Além disso, histopatologicamente apresenta-se como uma dermatite crônica com infiltrado mononuclear e eosinofílico (Miyakawa et al. 2009).

No estágio mais avançado da fotodermatite, os aspectos clínicos podem assemelhar-se às lesões ocasionadas por Pytium insidiosum em bovinos, no entanto, no exame histológico observam-se granulomas e piogranulomas multifocais com hifas de P. insidiosum no centro, circundadas ou não por reação de Splendore-Hoeppli (Pérez et al. 2005, Pereira \& Meireles 2007). Já nafotossensibilização hepatógena, ou secundária, além das lesões cutâneas características, os animais podem desenvolver sintomatologia nervosa (Schild 2007), o que não foi verificado no presente estudo. Além das diferenças descritas, as lesões de fotossensibilização pela ingestão de F. humbolditiana diferenciam-se de outras doenças por regredirem quando os animais são colocados na sombra e impedidos de ingerir a planta (Knupp et al. 2014).

Neste surto, os bezerros que estavam ingerindo o leite de vacas que apresentaram fotodermatite ocasionada pela ingestão de ervanço não desenvolveram a doença, portanto o componente tóxico da planta provavelmente não é excretado pelo leite, ou pode estar presente em menor quantidade, não ocasionando dessa forma a fotossensibilização. 0 mesmo foi descrito em cabritos que ingeriam o leite de cabras acometidas por fotossensibilização primária causada pela ingestão de F. humboldtiana (Santos et al. 2016).

Um fator importante a ser destacado quanto à ingestão de plantas tóxicas pelos animais é que as toxinas podem ser transferidas para o homem através do consumo de leite, causando um impacto não apenas econômico ao produtor rural, mas também na saúde pública. Nos Estados Unidos existe uma doença conhecida como enfermidade do leite ("milksickness"), que pode levar ao óbito de pessoas caso ocorra o consumo de leite de vacas em pastagens invadidas por Eupatorium rugosum (Panter \& James 1990, James 1994). Outras toxinas que podem ser eliminadas pelo leite são os alcalóides pirrolizidínicos (Dickinson et al. 1976), as saponinas esteroidais (Lemos et al. 1998), as monocrotalinas (Medeiros \& Górniak 1995, Medeiros et al. 1998, 1999) e o ptaquilosídeo, que é o princípio ativo de Pteridium aquilinum (James 1994). Além destes compostos, a toxina tremorgênica da Ipomoea asarifolia também é excretada pelo leite (James 1994, Lopes et al. 2014, Lucena et al. 2014).

0 risco de intoxicação em humanos por toxinas excretadas no leite é reduzido após o processo de industrialização, por que se mistura o leite de diversas origens diluindo as prováveis toxinas. No entanto, no Brasil e em outros países subdesenvolvidos, o risco de intoxicação por toxinas no leite persiste em pequenas cidades ou em propriedades rurais onde ainda se consume o leite in natura (Riet-Correa \& Medeiros 2001).

\section{CONCLUSÃO}

Froelichia humboldtiana é uma importante causa de fotossensibilização primária em bovinos leiteiros no semiárido brasileiro, podendo resultar em perdas econômicas significativas aos produtores rurais.

Agradecimentos.- Este estudo foi realizado com apoio da CAPES (Coordenação de Aperfeiçoamento de Pessoal de Nível Superior, Brasil) por meio de bolsa do Programa Pós-Graduação em Medicina Veterinária e Programa de Doutorado Sanduíche no Exterior (Proc. no. 8418/2014).

\section{REFERÊNCIAS}

Barbosa J.D., Oliveira C.M.C., Albernaz T.T., Silva N.S., Silveira J.A.S., Reis A.S.B. \& Sousa M.G.S. 2011. Dermatite por lambedura em bovinos no estado do Pará. Pesq. Vet. Bras. 31(2):136-138. http://dx.doi.org/10.1590/S0100736X2011000200007.

Dickinson J.O., Cooke M.P., King R.R. \& Mohamed P.A. 1976. Milk transfer of pyrrolizidine alkaloids in cattle. J. Am. Vet. Med. Assoc. 169(11):11921196. PMid:1002587.

Idema 2008. Perfil do seu Município, Assú/RN. Perfil do Seu Município, Natal 10:1-24. Disponível em <http://adcon.rn.gov.br/ACERVO/idema/DOC/ DOC000000000016656.PDF> Acesso em 22 nov. 2016.

James L.F. 1994. Solving poisonous plant problems by a team approach, p.1-6. In: Colegate S.M. \& Dorling P.R. (Eds), Plant Associated Toxins. CAB International, Wallingford.

Johnson S.J., Parker R.J., Norton J.H., Jaques P.A. \& Grimshaw A.A. 1981 Stephanofilariasis in cattle. Aust. Vet. J. 57(9):411-413. http://dx.doi. org/10.1111/j.1751-0813.1981.tb00544.x. PMid:7325911.

Knight A.P. \& Walter R.G. 2001. Plants affecting the liver and skyn, p.142-143. In: Ibid. (Eds), A Guide to Plant Poisoning of Animals in North America. New Media, Teton, USA.

Knupp S.N.R., Borburema C.C., Oliveira Neto T.S., Medeiros R., Knupp L.S., Riet-Correa F. \& Lucena R.B. 2014. Surtos de fotossensibilização primária em equídeos causados por Froelichia humboldtiana. Pesq. Vet. Bras. 34(12):1191-1195. http://dx.doi.org/10.1590/S0100-736X2014001200008.

Lemos R.A.A., Nakazato L. \& Pozo Del C.F. 1998. Intoxicação por Brachiaria sp., p.299-306. In: Lemos R.A.A. (Ed.), Principais Enfermidades de Bovinos de Corte do Mato Grosso do Sul. Universidade Federal do Mato Grosso do Sul, Campo Grande, MS.

Lopes J.R.G., Riet-Correa F., Cook D., Pfister J.A. \& Medeiros R.M.T. 2014 Elimination of the tremorgenic toxin of Ipomoea asarifolia by milk Pesq. Vet. Bras. 34(11):1085-1088. http://dx.doi.org/10.1590/S0100736X2014001100009.

Lucena K.F.C., Rodrigues J.M.N., Campos É.M., Dantas A.F.M., Pfister J.A., Cook D., Medeiros R.M.T. \& Riet-Correa F. 2014. Poisoning by Ipomoea 
asarifolia in lambs by the ingestion of milk from ewes that ingest the plant. Toxicon 92:129-132. http://dx.doi.org/10.1016/j.toxicon.2014.10.019. PMid:25448387.

Macedo M.C., Bezerra M.B. \& Soto-Blanco B. 2006. Fotossensibilização em animais de produção na região semi-árida do Rio Grande do Norte. Arqs Inst. Biológico, São Paulo, 73:251-254.

Marchioretto M.S., Windisch P.G. \& Siqueira J.C. 2002. Os gêneros Froelichia Moench e Froelichiella R.E. Fries (Amaranthaceae) no Brasil. Pesq. Bot. 52:7-46.

Medeiros R.M.T. \& Górniak S.L. 1995. Efeitos da administração de sementes de Crotalaria spectabilis e monocrotalina (MCT) na ração de ratas em lactação, no desenvolvimento físico de seus filhotes. Revta Soc. Bras. Toxicologia, IX Congresso Brasileiro de Toxicologia, Ribeirão Preto, SP, p.296. (Resumo)

Medeiros R.M.T., Bezerra V.K.D. \& Riet-Correa F. 2014. Intoxicação experimental por Froelichia humboldtiana em equinos. Ciência Rural 44(10):1837-1840. http://dx.doi.org/10.1590/0103-8478cr20131417.

Medeiros R.M.T., Górniak S.L. \& Guerra J.L. 1998. Comparative effects of prenatal and postnatal monocrotaline effects in rats, p.312-16. In: Garland T. \& Barr A.C. (Eds), Toxic Plants and Other Natural Toxicants. CAB International, New York

Medeiros R.M.T., Górniak S.L. \& Guerra J.L. 1999. Effects of milk from goat fed Crotalaria spectabilis seeds on growing rats. Braz. J. Vet. Res. Anim. Sci. 36(2):0. http://dx.doi.org/10.1590/S1413-95961999000200008.

Miyakawa V.I., Reis A.C.F. \& Lisbôa J.A.N. 2009. Aspectos epidemiológicos e clínicos da estefanofilariose em vacas leiteiras e comparação entre métodos de diagnóstico. Pesq. Vet. Bras. 29(11):887-893. http://dx.doi. org/10.1590/S0100-736X2009001100004.
Panter K.E. \& James L.F. 1990. Natural plant toxicants in milk: a review. J. Anim. Sci. 68(3):892-904. http://dx.doi.org/10.2527/1990.683892x. PMid:2180885.

Pereira D.B. \& Meireles M.A. 2007. Pitiose, p.457-466. In: Riet-Correa F., Schild A.L., Lemos R.A.A. \& Borges J.R.J. (Eds), Doenças de Ruminantes e Equídeos. Vol.1. $3^{\underline{a}}$ ed. Pallotti, Santa Maria, RS. 719p.

Pérez R.C., Luis-León J.J., Vivas J.L. \& Mendoza L. 2005. Epizootic cutaneous pytiosis in beef calves. Vet. Microbiol. 109(1/2):121-128. http://dx.doi. org/10.1016/j.vetmic.2005.04.020. PMid:15961262.

Pimentel L.A., Riet-Correa F., Guedes K.M., Macêdo J.T.S.A., Medeiros R.M.T. \& Dantas A.F.M. 2007. Fotossensibilização primária em equídeos e ruminantes no semi-árido causada por Froelichia humboldtiana (Amaranthaceae). Pesq. Vet. Bras. 27(1):23-28. http://dx.doi.org/10.1590/S0100-736X2007000100005.

Riet-Correa F. \& Medeiros R.M.T. 2001. Intoxicações por plantas em ruminantes no Brasil e no Uruguai: importância econômica, controle e riscos para a saúde pública. Pesq. Vet. Bras. 21(1):38-42. http://dx.doi.org/10.1590/ S0100-736X2001000100008.

Santos D.S., Silva C.C.B., Araújo V.O., Souza M.F., Lacerda-Lucena P.B., Simões S.V.D., Riet-Corrêa F. \& Lucena R.B. 2016. Primary photosensitization caused by ingestion of Froelichia humboldtiana by dairy goats. Toxicon 125:6569. http://dx.doi.org/10.1016/j.toxicon.2016.11.258. PMid:27890773.

Schild A.L. 2007. Fotossensibilização hepatógena, p.39-42. In: Riet-Correa F., Schild A.L., Lemos R.A.A. \& Borges J.R.J. (Eds), Doenças de Ruminantes e Eqüídeos. Vol. 2. 3ª ed. Pallotti, Santa Maria, RS. 694p.

Souza P.E.C., Oliveira S.S., Aguiar-Filho C.R., Cunha A.L.B., Albuquerque R.F., Evêncio-Neto J., Riet-Correa F. \& Mendonça F.S. 2012. Primary photosensitization in cattle caused by Froelichia humboldtiana. Res. Vet. Sci. 93(3):1337-1340. http://dx.doi.org/10.1016/j.rvsc.2012.04.005. PMid:22575746. 